\title{
The role of varicocele sclerotherapy in men with severe oligo-astheno-teratozoospermia
}

\begin{abstract}
Mazen A Ghanem ${ }^{1,2}$, Manal A Safan ${ }^{3}$, Ashraf A Ghanem ${ }^{4}$ and Gert R Dohle ${ }^{2}$
The aim of this study was to verify the role of antegrade scrotal sclerotherapy for the treatment of varicoceles in infertile men with severe oligo-astheno-teratozoospermia (OAT). The 59 patients with severe OAT in this study underwent antegrade scrotal sclerotherapy for the treatment of varicoceles. The outcome was assessed in terms of improvement in semen parameters and spontaneous conception rate. Semen parameters and reproductive hormones were evaluated before antegrade sclerotherapy (AS) and 6 months after AS. After an average follow-up time of $34.8 \pm 3.2$ months, significant improvement was noted in the mean sperm concentration, motility and morphology in 36 patients (61\%). Spontaneous pregnancy occurred in nine couples (15\%). Six months after treatment, inhibin B levels were significantly higher $(\boldsymbol{P}<0.04)$, whereas follicle-stimulating hormone (FSH) levels were significantly lower $(\boldsymbol{P}<0.001)$ than before treatment. Antegrade internal spermatic vein sclerotherapy can significantly improve seminal parameters and hormonal parameters in men with severe OAT and may even result in spontaneous pregnancy in couples who would otherwise be candidates for intracytoplasmic sperm injection (ICSI).
\end{abstract}

Asian Journal of Andrology (2011) 13,867-871; doi:10.1038/aja.2011.48; published online 25 July 2011

Keywords: infertility; Inhibin B; oligo-astheno-teratozoospermia; sclerotherapy; semen parameters; varicocele

\section{INTRODUCTION}

Varicoceles are present in $25 \%$ of males with fertility problems and can be associated with abnormal semen analysis results. ${ }^{1}$ Several studies have confirmed an association between varicocele and testicular dysfunction, reflected by abnormal semen and the loss of testicular volume. $^{2-6}$

Many procedures have been used for primary varicocele treatment, such as open spermatic vein ligation, laparoscopy, microsurgery and antegrade sclerotherapy (AS). The clinical benefit of varicocele repair has been shown to be the improvement in seminal parameters, although there is controversy about whether this improvement leads to an increased chance of natural conception. A Cochrane database showed no treatment benefit of varicocele repair on a couple's chances of conception over couple's controls. ${ }^{7-10}$ This absence of a benefit of the treatment may be the result of a failure to select patients who are likely to benefit from treatment, such as men with a clinical varicocele, abnormal semen and otherwise unexplained infertility. ${ }^{11-15}$

Only a few reports on the role of AS in patients with severe oligoastheno-teratozoospermia (OAT) have been published. ${ }^{16,17}$ In this study, we evaluated the treatment outcome of AS in these patients.

\section{MATERIALS AND METHODS}

Patients

The 256 patients referred to our division of andrology for infertility were diagnosed with varicocele between August 2002 and November 2009. From this group, 107 patients were diagnosed with OAT syndrome and manifested all of the following cutoff abnormalities: decreased number of spermatozoa ( $\leqslant 3$ million spermatozoa $\mathrm{ml}^{-1}$ ), decreased motility of spermatozoa ( $\leqslant 15 \%$ motile spermatozoa) and many abnormal forms of spermatozoa on morphological examination ( $\leqslant 14 \%$ normal forms). The 27 varicocele patients with OAT who did not undergo any surgical intervention or medical treatment were included as a control group. The mean age of the patients in the control group was $33.6 \pm 1.7$ years (range: $22-42$ years).

\section{Clinical examination}

Varicocele was diagnosed in men with fertility problems. All patients underwent physical examination in an upright position with the aid of the Valsalva manoeuvre. Clinical varicocele was graded according to the recommendations of the World Health Organization (1993). ${ }^{18}$ Subsequently, these patients underwent Doppler ultrasonography of the scrotum (Nemio 20 with a $12-\mathrm{Hz}$ transducer) with the Valsalva manoeuvre performed by the same operator before the procedure and 6 months after the sclerotherapy. The testicular volume was calculated using the following formula: volume $(V)=1 / 6$ length width ${ }^{2}{ }^{19}$ The following criteria had to be included in addition to a Valsalva-positive varicocele: infertility persisting longer than 1 year despite regular, unprotected intercourse; and OTA assessed according to World Health Organization guidelines (1992). ${ }^{1}$ In addition, the partners of these patients were evaluated for exclusion of the definite causes of infertility, such as anovulation, endometriosis or tubal blockage. Patients who were negative for the presence of other urogenital diseases (e.g., a history of cryptorchidism or severe STDs), 
recurrent varicocele, sperm antibodies, and endocrinological and internal diseases (e.g., chronic liver, renal, etc.) were enrolled.

\section{Laboratory analysis}

Serum inhibin B, follicle-stimulating hormone (FSH) and testosterone levels were evaluated at baseline and 6 months after the sclerotherapy and 6 months after the basal examination in the control group. Serum inhibin B was measured with an enzyme immunoassay according to the method previously described by Lambert-Msserlian et al. ${ }^{20}$ and Groome et al. ${ }^{21}$ Serum FSH was determined with the Immulite automated analyser (Immulite; Diagnostic products Corporation, Los Angeles, CA, USA). Serum total testosterone was measured using the electrochemiluminescence immunoassay method (Elecys 1010; Boehringer Mannheim, Mannheimm, Germany). ${ }^{22,23}$

Semen analysis was performed according to World Health Organization guidelines (1999). ${ }^{24}$ The sperm concentration (million $\mathrm{ml}^{-1}$ ), the percentage of motile sperm cells and the percentage of morphologically normal forms were assessed. The semen analysis data from each patient are represented as the mean of three evaluations performed within 6 months before and after treatment. ${ }^{25}$

AS

The AS procedure was performed with the patient under local anaesthesia and antibiotic prophylaxis ( $250 \mathrm{mg}$ ciprofloxacine) according to the technique described by Tauber and Johnsen. ${ }^{26}$ Three to four millilitres of sclerosant hydroxy-polyaethoxy-dodecanol (ethoxysclerol, $3 \%$ ) was injected into the internal spermatic vein using the air block technique. Further details of the percutaneous sclerotherapy technique have been described by Di Bisceglie et al. ${ }^{27}$

\section{Evaluation methods}

The mean postoperative follow-up period was $34.8 \pm 3.2$ months (range: 6-76 months) and included clinical and Doppler ultrasound assessment of all patients. A clinical examination and duplex ultrasonography of the testicles was performed $\geqslant 3$ months after AS (3-6 months). Treatment success was defined as the disappearance of the varicocele both clinically and based on Doppler ultrasonography and in some cases, improvements in seminal parameters and conception. The improvement in semen parameters was defined as an increase in sperm concentration ( $\geqslant 3$ million spermatozoa $\mathrm{ml}^{-1}$ ), the percentage of progressive motile sperm cells ( $\geqslant 15 \%$ motile spermatozoa) and normal sperm morphological forms ( $\geqslant 14 \%$ normal forms). Followup of the couples consisted of 3-month interval visits for a period of 12 months. Spontaneous pregnancy data were collected. An artificial reproductive technique (ART) pregnancy was determined by the presence of serum Human Chorionic Gonadotrophine of $>20$ IU on day 14 following embryo transfer, followed by a 2 -month scan for the presence of a foetal heartbeat.

\section{Statistical analysis}

Statistical analysis was performed using the SPSS 14.0 software package (SPSS Inc., Chicago, IL, USA). Results are expressed as mean \pm s.e.m. Comparison between the two groups was accomplished using Chi-square tests. The statistical significance of any change in the hormonal values was tested using the spearman rank correlation, and $P<0.05$ was considered significant.

\section{RESULTS}

The 64 patients with OAT underwent radiological sclerotherapy of the internal spermatic vein; 59/64 patients had successful AS, resulting in a failure rate of 5/64 (8\%) that was mainly due to technical problems, such as difficult access to the internal spermatic vein. In these 59 patients, a left-sided varicocele was present in $52(88 \%)$ and bilateral varicocele in $7(12 \%)$ patients. In addition, 52 (88\%) of these patients were diagnosed with grade I varicocele, whereas 7 (12\%) had grade II varicocele (Table 1). The mean age of this group was $32.7 \pm 1.1$ years (range: 22-43 years).

Six months after treatment, Doppler ultrasonography examination showed a complete resolution of the varicocele in 59 patients with successful AS. No significant changes in the right and left testicular volume were observed after AS during the 6-month follow-up period (right: $19.3 \pm 3.8 \mathrm{ml}$ vs. $19.2 \pm 3.9 \mathrm{ml}$; left: $18.8 \pm 3.9 \mathrm{ml} v s$. $18.7 \pm 3.8 \mathrm{ml} ; P>0.05)$. Semen analysis after treatment showed a significant improvement in sperm concentration $\left(6.5 \pm 0.5 \times 10^{6} \mathrm{ml}^{-1} v\right.$. $\left.2.2 \pm 0.2 \times 10^{6} \mathrm{ml}^{-1}, P<0.05\right)$ and progressive motility $(32.4 \% \pm 1.2 \%$ vs. $13.6 \% \pm 0.9 \%, P<0.05)$. In addition, significant changes in normal sperm morphology were observed $(35.9 \% \pm 1.4 \%$ vs. $11.9 \% \pm 0.2 \%$, $P<0.05$ ) (Table 2). A significant increase in semen parameters was observed in 36 patients (61\%).

Inhibin B levels were increased after AS compared to before the procedure (mean \pm s.e.m., $167.6 \pm 2.1$ vs. $132.8 \pm 3.2 \mathrm{pg} \mathrm{ml}^{-1}, P<0.05$ ), whereas FSH levels were decreased after AS $\left(7.1 \pm 0.3 \mathrm{mIU} \mathrm{ml}^{-1}\right.$ vs. $\left.9.9 \pm 0.4 \mathrm{mIU} \mathrm{ml} \mathrm{ml}^{-1}, P<0.001\right)$. No significant changes in serum testosterone were observed after AS $\left(8.3 \pm 1.1 \mathrm{ng} \mathrm{ml}^{-1}\right.$ vs. $8.1 \pm 1.2$ ng $\mathrm{ml}^{-1}, P>0.05$ ) (Table 3). A significant negative correlation between FSH and inhibin B levels was found between pre- and post-treatment values $(r=-0.617, P<0.001 ; r=-0.382, P<0.003$; respectively).

In the five patients with unsuccessful procedures, no significant variations in seminal parameters were observed 6 months after the basal examination (sperm concentration, $3.7 \pm 0.5 \times 10^{6} \mathrm{ml}^{-1}$ vs. $3.9 \pm 0.5 \times$ $10^{6} \mathrm{ml}^{-1}$; progressive motility, $20.6 \% \pm 0.6 \%$ vs. $21.8 \% \pm 0.1 \%$; normal sperm morphology, $11.6 \% \pm 0.5 \%$ vs. $12.8 \% \pm 0.2 \%$ ). In addition, no significant variations in hormonal levels were observed 6 months after the basal examination (inhibin B, $151.1 \pm 5.3 \mathrm{pg} \mathrm{ml}^{-1}$ vs. $150.5 \pm 5.2$ pg ml${ }^{-1}$; FSH, 9.2 $\pm 0.6 \mathrm{mIU} \mathrm{ml}^{-1}$ vs. $9.4 \pm 0.6 \mathrm{mIU} \mathrm{ml}^{-1}$; testosterone, $8.3 \pm 6.3 \mathrm{ng} \mathrm{ml}^{-1}$ vs. $8.2 \pm 6.2 \mathrm{ng} \mathrm{ml}^{-1}$ ).

In the control group, no significant variations in seminal parameters were observed 6 months after the basal examination (sperm concentration, $2.4 \pm 0.3 \times 10^{6} \mathrm{ml}^{-1}$ vs. $2.6 \pm 0.4 \times 10^{6} \mathrm{ml}^{-1}$; progressive motility, $13.9 \% \pm 1.1 \%$ vs. $14.9 \% \pm 1.1 \%$; normal sperm morphology, $13.1 \% \pm 0.4 \%$ vs. $12.6 \% \pm 0.3 \%$ ) (Table 2 ). A significant difference was found between the seminal parameters (sperm concentration, progressive motility and normal sperm morphology) in the treated and control subjects $(P<0.05)$ (Table 2$)$. No significant changes in testicular volume were observed during the 6-month follow-up period (right: $20.8 \pm 1.9 \mathrm{ml}$ vs. $19.8 \pm 1.8 \mathrm{ml}$; left: $19.9 \pm 1.5 \mathrm{ml} v s .18 .9 \pm 1.8 \mathrm{ml}$; $P>0.05)$.

\section{Table 1 Patient demographic data}

\begin{tabular}{ll}
\hline Characteristics & Value \\
\hline Patients ( $n$ ) & 59 \\
Mean age (year) & 32.7 \\
Mean follow-up (month) & 34.8 \\
Varicocele ( $n$ ) & 52 \\
$\quad$ Grade I & 7 \\
Grade II & 52 \\
Left-sided & 7 \\
Bilateral & 4 \\
Complications $(n)$ & \\
\hline
\end{tabular}


Table 2 Semen parameters before and after 6-month follow-up examinations in both the patient and control groups

\begin{tabular}{|c|c|c|c|c|c|c|}
\hline \multirow{2}{*}{ Semen parameter } & \multicolumn{3}{|c|}{ Patient group } & \multicolumn{3}{|c|}{ Control group } \\
\hline & Before AS & After AS & $\mathrm{P}^{*}$ value & Before 6 months & After 6 months & $\mathrm{P}^{* *}$ value \\
\hline Sperm concentration (million $\mathrm{ml}^{-1}$ ) & $2.2 \pm 0.2$ & $6.5 \pm 0.5$ & $<0.05$ & $2.4 \pm 0.3$ & $2.6 \pm 0.4$ & $<0.05$ \\
\hline Sperm motility (\%) & $13.6 \pm 0.9$ & $32.4 \pm 1.2$ & $<0.05$ & $14.9 \pm 1.1$ & $13.9 \pm 1.1$ & $<0.05$ \\
\hline Sperm normal morphology (\%) & $11.9 \pm 0.2$ & $35.9 \pm 1.4$ & $<0.05$ & $12.6 \pm 0.3$ & $13.1 \pm 0.4$ & $<0.05$ \\
\hline
\end{tabular}

Abbreviation: AS, antegrade sclerotherapy.

* $P$ value (Chi-square test, comparison between patient groups before and after AS).

${ }^{* *} P$ value (Chi-square test, comparison between the patient group after AS and the control group).

In the control group, no significant variations in hormonal levels were observed 6 months after the basal examination (inhibin B, $124.8 \pm 2.4 \mathrm{pg} \mathrm{ml}^{-1}$ vs. $126.5 \pm 2.7 \mathrm{pg} \mathrm{ml}^{-1}$; FSH, $10.2 \pm 0.5 \mathrm{mIU}$ $\mathrm{ml}^{-1}$ vs. $10.4 \pm 0.6 \mathrm{mIU} \mathrm{ml}^{-1}$; testosterone, $8.2 \pm 1.3 \mathrm{ng} \mathrm{ml}^{-1}$ vs. $\left.8.1 \pm 1.4 \mathrm{ng} \mathrm{ml}^{-1}\right)$. Compared to the control subjects, inhibin B levels were significantly higher $(P<0.05)$, whereas FSH levels were significantly lower $(P<0.05)$ in treated subjects.

Of the 59 patients, nine (15\%) had a successful spontaneous pregnancy within $6.4 \pm 5.4$ months after AS. The semen parameters were significantly higher in post-treatment subjects who initiated a spontaneous pregnancy than those that did not (sperm concentration, $13.1 \pm 1.3 \times 10^{6} \mathrm{ml}^{-1}$ vs. $5.3 \pm 1.5 \times 10^{6} \mathrm{ml}^{-1}$; progressive motility, $56.1 \% \pm 2.2 \%$ vs. $27.7 \% \pm 1.2 \%$; normal sperm morphology, $43.3 \% \pm 2.4 \%$ vs. $34.6 \% \pm 1.8 \%, P<0.05)$. No significant correlation was found between the side and grade of the varicocele, semen parameter improvements and pregnancy rates.

The 47 couples were treated by ART to aid conception, including intracytoplasmic sperm injection (ICSI) (31/47), in vitro fertilisation (IVF) (9/47) and intrauterine insemination (IUI) (7/47). ART resulted in pregnancy rates of $32.3 \%$ (10/31), 22.2\% (2/9) and $14.3 \%(1 / 7)$ by ICSI, IVF and IUI, respectively, within $16.2 \pm 4.6$ months of AS. The live birth rates were $29 \%, 22 \%$ and $14 \%$ for ICSI, IVF and IUI, respectively. The mean partner age of the pregnant group at varicocele repair (either spontaneous or ART) was $31.6 \pm 3.2$ years, whereas the average age was $33.8 \pm 4.3$ years in the non-pregnant group. Three female partners were diagnosed with irregular menstrual cycles that were successfully treated with clomiphene citrate. Six females in the partner group also underwent unsuccessful IUI prior to AS.

Four patients suffered minor complications as a result of AS: two cases experienced spermatic cord inflammation that was resolved with antibiotics, and two men had superficial wound infections. No patients developed a hydrocele after surgery.

\section{DISCUSSION}

Varicocele is a pathological condition present in $11 \%$ of the male population and in $25 \%$ of infertile men. ${ }^{1}$ A recent meta-analysis of the literature showed that varicocele repair significantly improves sperm parameters (both sperm concentration and motility). ${ }^{28}$ Improvements in semen parameters have been observed in $60 \%$ $80 \%$ of men after varicocele correction. ${ }^{26}$

Table 3 Changes in hormonal levels before treatment and at the 6month post-treatment follow-up examinations

\begin{tabular}{lccc}
\hline Parameter & Before treatment & After treatment & P value \\
\hline Inhibin B $\left(\mathrm{pg} \mathrm{ml}^{-1}\right)$ & $132.8 \pm 3.2$ & $167.6 \pm 2.1$ & $<0.05$ \\
FSH $\left(\mathrm{mlU} \mathrm{ml}^{-1}\right.$ ) & $9.9 \pm 0.4$ & $7.1 \pm 0.3$ & $<0.001$ \\
Testosterone $\left(\mathrm{ng} \mathrm{ml}^{-1}\right)$ & $8.1 \pm 1.2$ & $8.3 \pm 1.1$ & $>0.05$ \\
\hline
\end{tabular}

Abbreviation: $\mathrm{FSH}$, follicle-stimulating hormone.
However, data on the effect of AS treatment on semen parameters and pregnancy rates, especially in patients with severe oligospermia, are limited. In the present study, this technique was demonstrated to be effective at improving semen parameters in patients with this condition. In addition, spontaneous pregnancies were discovered during follow-up in $15 \%$ of couples that otherwise had a very low chance of natural conception based on their sperm parameters. Usually, these couples are referred for ICSI. In cases in which there was no spontaneous pregnancy, the sperm improvement allowed an upgrade of ART, from ICSI to IVF and IUI. ${ }^{17,29}$

Our results are consistent with the report by Osmonov et al., ${ }^{17}$ who found that $53 \%$ of patients with initial non-obstructive azoospermia developed cryptozoospermia (OAT/OT syndrome) after AS, allowing ICSI as treatment. Another $60 \%$ of men with initial cryptozoospermia showed an improvement in the sperm count and motility. Poulakis et al. ${ }^{16}$ observed significantly higher sperm concentration, motility and normal morphology in a group of men with severe OAT, and pregnancy occurred in $15 \%$ of these couples. Testicular histopathology of azoospermic patients with postoperative induction of spermatogenesis revealed maturation arrest at the spermatid stage, Sertoli cell-only with focal spermatogenesis or hypospermatogenesis. None of the patients with a pure Sertoli cell-only pattern or maturation arrest at the spermatocyte stage achieved spermatogenesis after the treatment.

Testicular insufficiency can occur in men with varicoceles and is characterized by pathological changes in the seminiferous tubule structure, impaired spermatogenesis, abnormal sperm motility, quality and the number of spermatogonia and the loss of testicular volume and consistency. These symptoms may improve after varicocele repair. ${ }^{6}$ AS can be performed under local anaesthesia and is a reliable, effective and minimally invasive procedure with a short operation time. Patients can usually return to normal activities within a few days. This technique is a cost-saving technique compared to other surgical techniques such as laparoscopy, microsurgery and microsurgical sperm retrieval. ${ }^{30-32}$ In addition, the specific treatment of varicocele-associated male factor infertility with surgical varicocelectomy is more cost-effective than primary treatment with assisted reproduction. ${ }^{33}$ However, AS requires a physician with experience in interventional radiology and has a failure rate of $4 \%-27 \% .^{34}$

We also observed an increase in serum inhibin B after treatment, suggesting an improvement in Sertoli cell function and spermatogenesis as a result of AS treatment. ${ }^{35}$ Moreover, the concomitant decrease in FSH further supports this observation and indicates restoration of the negative feedback mechanism. We also found an inverse correlation between inhibin B and FSH in men with OAT. The changes in inhibin $\mathrm{B}$ and $\mathrm{FSH}$ in the follow-up period indicate rapid and reversible recovery of spermatogenesis in varicocele patients. ${ }^{23,36}$ These rapid changes may be attributed to the younger age of patient studied compared to the study by Byrd et al. ${ }^{37}$ In addition, the shorter 
duration of varicocele intervention and the grade I varicoceles of the majority of the patients, which do not lead to permanent spermatogenesis damage, may be related to this rapid changes.

Despite the encouraging sperm improvement after AS, the rate of natural conception is still lower than that reported after surgical repair. ${ }^{15,25}$ Spontaneous pregnancy rates were $41.9 \%$ after the microsurgical varicocelectomy techniques, $37.7 \%$ after the Palomo technique, $36 \%$ after the macroscopic inguinal (Ivanissevich) techniques and $30.1 \%$ after the laparoscopic varicocelectomy techniques, compared to $33.2 \%$ after radiological embolisation. ${ }^{34}$ These differences, however, may be explained by several factors, including semen quality before the operation and female fertility. ${ }^{38,39}$ In addition, regular medical counselling for the infertile couples is as effective as the surgical or angiographic treatment of varicoceles at achieving pregnancy. ${ }^{12}$

Although spontaneous pregnancies occurred in 15\% of the couples, many couples still required ART for conception. In our study, most patients had severe OAT. In these patients, ICSI showed a significantly better pregnancy rate than IUI and IVF. ${ }^{40,41}$ Mangoli et al. ${ }^{41}$ found that ICSI showed a significantly higher pregnancy rate (29\%) over IVF (13.2\%) for men with OAT, whereas IVF showed a significant advantage over IUI (pregnancy rate of $8 \%$ ).

Despite the relatively low number of pregnancies after AS and severe OAT in our study, ICSI was the only option for these couples. Therefore, the $15 \%$ spontaneous pregnancy rate in this group should be considered an acceptable result.

It should be emphasized that most men in our population had severe OAT, although the majority were grade I varicoceles. This raises the hypothesis that varicoceles in this group of patients are associated with underlying genetic or epigenetic factors that contribute to infertility, ${ }^{42}$ which may explain the heterogeneous clinical presentation in men with a varicocele and the variable response to varicocelectomy. ${ }^{43}$ Therefore, future prospective studies should include genetic investigations (e.g., karyotyping and searching for Y-chromosome deletions) to characterize these patients. This is of particular interest because it is not known whether or not the treatment of varicoceles in patients with genetic aberrations is useful.

In conclusion, this study shows that AS is an effective procedure that is associated with an improvement in sperm parameters, an increase of inhibin B and a reduction of FSH in men with severe OAT. This treatment also resulted in a $15 \%$ spontaneous pregnancy rate. However, complete normalisation of the spermiogram parameters cannot be expected with this method. Despite this, improvements in semen parameters resulted in an upgrade in the type of ART that could be used to aid conception.

\section{AUTHOR CONTRIBUTIONS}

MG and GD performed the surgical procedures. MS performed the laboratory analysis, while AG performed and monitored the ART procedures and pregnancy outcome. All authors participated in the design and coordination of the study and sequence alignment and drafted the manuscript. All authors read and approved the final manuscript.

\section{COMPETING FINANCIAL INTERESTS}

This article was not funded by any organisation, and the authors did not have any financial relationships with any organisation to conduct this study. In addition, the authors declare that they have no conflicts of interest.

1 World Health Organization. The influence of varicocele on parameters of fertility in a large group of men presenting to infertility clinics. Fertil Steril 1992; 57: 1289-93.
2 Hadziselimovic F, Herzog B, Liebundgut B, Jenny P, Buser M. Testicular and vascular changes in children and adults with varicocele. J Urol 1989; 142: 583-5.

3 Sayfan J, Siplovich L, Koltun L, Benyamin N. Varicocele treatment in pubertal boys prevents testicular growth arrest. J Urol 1997; 157: 1456-7.

4 Paduch A, Niedzieliski J. Repair versus observation in adolescent varicocele: a prospective study. J Urol 1997; 158: 1128-32.

5 Lund L, Tang YC, Roebuck D, Lee KH, Liu K et al. Testicular catch-up growth after varicocele correction in adolescent. Pediatr Surg Int 1999; 15: 234-7.

6 Cayan S, Akbay E, Bozlu M, Doruk E, Erdem E et al. The effect of varicocele repair on testicular volume in children and adolescent with varicocele. J Urol 2002; 168: 731-4.

7 Goldstein M, Gilbert BR, Dicker AP, Dwosh J, Gnecco C. Microsurgical inguinal varicocelectomy with delivery of the testis: an artery and lymphatic sparing technique. J Urol 1992; 148: 1808-11.

8 Abdulmaaboud MR, Shokeir AA, Farage Y, El-Rahaman AA, El-Rakhaway MM et al. Treatment of varicocele: a comparative study of conventional open surgery, percutaneous retrograde sclerotherapy and laparoscopy. Urology 1998; 52: 294-300.

9 Pintus C, Rodriguez Matas MJ, Manzoni C, Nanni L, Perrelli L. Varicocele in paediatric patients: comparative assessment of different therapeutic approaches. Urology 2001; 57: 154-7.

10 Tauber R, Pfeiffer D. Antegrade sclerotherapy for varicocele testis-possible and avoidable complications. Urologe A 2003; 42: 1238-43.

11 Evers JL, Collins JA. Surgery or embolisation for varicocele in subfertile men. Cochrane Database Syst Rev 2004; (1): CD000479.

12 Nieschlag E, Hertle L, Fischedick A, Abshagen K, Behre HM. Update on treatment of varicocele: counseling as effective as occlusion of the vena spermatica. Hum Reprod 1998; 13: 2147-50.

13 Kamischke A, Nieschlag E. Varicocele treatment in the light of evidence-based andrology. Hum Reprod Update 2001; 7: 65-9.

14 Marmar JL, Benoff S. The safety of ultrasonically guided testis aspiration biopsies and efficacy of use to predict varicocelectomy outcome. Hum Reprod 2005; 20: 2279-88.

15 Marmar JL, Agarwal A, Prabakaran S, Agarwal R, Short RA et al. Reassessing the value of varicocelectomy as a treatment for male subfertility with a new meta-analysis. Fertil Steril 2007; 88: 639-48.

16 Poulakis V, Ferakis N, de Vries R, Witzsch U, Becht E. Induction of spermatogenesis in men with azoospermia or sever oligoteratoasthenospermia after antegrade internal spermatic vein sclerotherapy for the treatment of varicocele. Asian J Androl 2006; 8: 613-9.

17 Osmonov DK, van der Horst C, Weyel T, Danilevicius M, Braun PM et al. Induction of spermatogenesis in patients with non- obstructive azoospermia after antegrade sclerotherapy. Akt Urol 2006; 37: 132-7.

18 World Health Organization. Manual for the Standardized Investigation and Diagnosis of the Infertile Couple. Cambridge: Cambridge University Press; 1993.

19 Chipkevitch E, Nishimura RT, Tu DG, Galea-Rojas M. Clinical measurement of testicular volume in adolescents: Comparison of the reliability of methods. J Urol 1996; 156: 2050-3.

20 Lambert-Messerlian GM, Hall JE, Sluss PM. Relatively low levels specific two-site enzyme immunoassay. J Clin Endocrinol Metab 1994; 79: 45-50.

21 Groome NP, Illingrowth PJ, Brien M. Measurement of dimeric inhibin B through the human menstrual cycle. J Clin Endocrinol Metab 1996; 81: 1401-5.

22 de Waal WJ, Vreeburg JT, Bekkering F, de Jong FH, de Muinck Keizer-Schrama SM et al. High dose testosterone therapy for reduction of final height in constitutionally tall boys: does it influence testicular function in adulthood? Clin Endocrinol 1995; 43: 87-95.

23 Pierik FH, Vreeburg JTM, Stijnen T, de Jong FH, Weber RFA. Serum inhibin B as a marker of spermatogenesis. J Clin Endocrinol Metab 1998; 83: 3110-4.

24 World Health Organization. WHO Laboratory Manual for the Examination of the Human Semen and Sperm-Cervical Mucus Interaction. 4th ed. Cambridge: Cambridge University Press; 1999. p19.

25 Marmar JL, Kim Y. Subinguinal microsurgical varicocelectomy: a technical critique and statistical analysis of semen and pregnancy data. J Urol 1994; 152: 1127-32.

26 Tauber R, Johnsen N. Antegrade scrotal sclerotherapy for the treatment of varicocele: technique and late results. J Urol 1994; 151: 386-90.

27 Di Bisceglie C, Fornengo R, Grosso M, Gazzera C, Mancini A et al. Follow up of varicocele treated with percutaneous retrograde sclerotherapy: technical, clinical and seminal aspects. J Endocrinol Invest 2003; 26: 1059-64.

28 Agarwal A, Deepinder F, Cocuzza M, Argawal R, Short RA et al. Efficacy of varicocelectomy in improving semen parameters: new meta-analytical approach. Urology 2007; 70: 532-8.

29 Gat Y, Bachar GN, Everaert K, Levinger U, Gornish M. Induction of spermatogenesis in azoospermic men after internal spermatic vein embolization for treatment of varicocele. Hum Reprod 2005; 20: 1013-7.

30 Beutner S, May M, Hoschke B, Helke C, Lein M et al. Treatment of varicocele with reference to age: a retrospective comparison of three minimally invasive procedures. Surg Endosc 2007; 21: 61-5.

31 Di Bisceglie C, Bertagna A, Baldi M, Lanfranco F, Tagliabue F et al. Varicocele sclerotherapy improves serum inhibin $B$ levels and seminal parameters. Int J Androl 2007: 30: 531-6.

32 Lee R, Li PS, Goldstein M, Schattman G, Schlegel PN. A decision analysis of treatments for non-obstructive azoospermia associated with varicocele. Fertil Steril 2009; 92: 188-96.

33 Schlegel P. Is assisted reproduction the optimal treatment for varicocele-associated male infertility? A cost-effectiveness analysis. Urology 1997; 49: 83-90. 
34 Cayan S, Shavakhabov S, Kadioglu A. Treatment of palpable varicocele in infertile men: A meta-analysis to define the best technique. J Androl 2009; 30: 33-40.

35 Fisch H, Hyun G, Hensle TW. Testicular growth and gonadotrophin response associated with varicocele repair in adolescent males. BJU Int 2003; 91: 75-8.

36 Meachem SJ, Nieschlag E, Simoni M. Inhibin B in male reproduction: pathophysiology and clinical relevance. Eur J Endocrinol 2001; 145: 561-71.

37 Byrd W, Bennett MJ, Carr BR, Dong Y, Wians F et al. Regulation of biologically active dimeric inhibin A and B from infancy to adulthood in the male. J Clin Endocrinol Metab 1998; 83: 2849-54.

38 Rodriguez-Rigau LJ, Smith KD, Steinberger E. Relationship of varicocele to sperm output and fertility of male partners in infertile couples. J Urol 1978; 120: 691-4.
39 Brenznik R, Valaisavljevic V, Borko E. Treatment of varicocele and male fertility. Arch Androl 1993; 30: 157-60.

40 Bakos HW, Thompson JG, Feil D, Lane M. Sperm DNA damage is associated with assisted reproductive technology pregnancy. Int J Androl 2007; 31: 518-26.

41 Mangoli VS, Dandekar SP, Desai Sk, Mangoli R. The outcome of assisted reproductive technology in males with impaired spermatogenesis. J Hum Reprod Sci 2008; 1: 73-6.

42 Marmar JL. The pathophysiology of varicoceles in the light of current molecular and genetic information. Hum Reprod Update 2001; 7: 461.

43 Smit M, Romijn JC, Wildhagen MF, Veldhoven JL, Weber RF et al. Decreased sperm DNA fragmentation after surgical varicocelectomy is associated with increased pregnancy rate. J Urol 2010; 183: 270-4. 